\title{
Discourse practices in MOOC discussions
}

\section{A corpus linguistic approach}

\section{Shi Min Chua}

\section{I Introduction}

In massive open online courses (MOOCs) the discussion function allows learners to exchange information, experience and ideas with each other (Ferguson \& Sharples, 2014; Poquet, Dowell, Brooks, \& Dawson, 2018). The discussion has been hailed as beneficial for socio-constructive learning (Sharples \& Ferguson, 2019). In a socio-constructive process, humans co-construct meaning, knowledge and the social world through social interactions with others (Vygotsky, 1978). Language is one means for such co-construction. However, limited MOOC research has investigated learners' language practices in online discussions. Instead, most studies have focused on evaluating learners' comments in the discussion, such as whether a comment showed a learner engaged in critical thinking or a comment was on-topic (Kellogg, Booth, \& Oliver, 2014; Wen, Yang, \& Rosé, 2014; Wise, Cui, \& Vytasek, 2016). Other MOOC studies in the field of educational technology also centred on the implications for learning and technological design (Almatrafi \& Johri, 2019), as also illustrated in Chapters 5, 8, and 9 (Conde Gafaro, 2022; Iniesto, McAndrew, Minocha, \& Coughlan, 2022; Rizvi, Rienties, Kizilcec, \& Rogaten, 2022).

As will be elaborated in the next section, the analysis of learners' comments in MOOC discussions in previous studies was mainly quantitative in nature (Kellogg et al., 2014; Wen et al., 2014; Wise et al., 2016). However, the richness of the textual data in the learners' comments was often lost in the quantification process of these analyses, such that learners' discourse practices in the socioconstructive processes were not revealed. Therefore, there is a lack of understanding of learners' discourse practices in initiating and engaging in conversations with others in the MOOC discussions. Discourse practices refer to the recurring ways a community uses language to do things in their social context - above and beyond a sentence (Herring, 2004). To fill this gap in MOOC research, I conducted a corpus linguistic analysis of MOOC discussions in my $\mathrm{PhD}$ to explore discourse practices that facilitated and hampered conversations among learners. In this chapter, I will introduce this methodology and summarize the main findings from my $\mathrm{PhD}$ to illustrate the importance of language practices in MOOC discussions. 


\subsection{Previous research on MOOC online discussions}

To the best of my knowledge of the literature and based on the systematic review by Almatrafi \& Johri (2019), most studies on MOOC discussions used a coding and counting paradigm of content analysis to analyse learners' comments either manually or automatically by machine-learning techniques. The comments typically were analysed individually, rather than discursively to understand how a conversation was co-constructed by learners. These studies categorised learners' comments - for example, whether a comment was on-topic or off-topic (Wise et al., 2016), whether a comment indicated that a learner engaged in higher order thinking or paid attention (Wang et al., 2016) or whether a comment was positive or negative (Wen et al., 2014) - rather than how a comment was written, for example, how a question or a disagreement was raised to engage with others.

In these studies, learners' textual contributions were reduced to codes for counting purposes such that their comments in the discussion could be quantified and (cor)related to other variables statistically, such as learners' learning outcome, participation pattern, or course design, as, for example, done by Rizvi et al. (2022). The coding also formed the basis for automatic recommendation of quality comments to learners, monitoring of the discussion space, and prediction of learning performance (Almatrafi \& Johri, 2019; Wise et al., 2016). These studies were useful for evaluating the quality of the discussion, and might inform educators or designers for further improvement of their MOOCs.

However, equally important are the socio-constructive processes that are realised by learners' actual language and discourse practices (Vygotsky, 1978; Wegerif \& Mercer, 1997; Wise \& Paulus, 2016). Several researchers have argued that learners need to be aware of discourse practices that are suitable for online communications, especially for negotiation in online discussions (Herring, 2004). For example, in a small-scale online learning discussion, sharing of experience could be a way to reach agreement and affiliation in co-construction, or could be rejected by others as authoritative, depending on how learners oriented it in the ongoing discussion (Kääntä \& Lehtinen, 2016). In another online learning discussion, Littleton \& Whitelock (2005) found that in the process of socio-constructive learning, learners did not necessarily employ reasoning but could express uncertainty instead, for example, "Just some ideas which may or may not be of help". A learner also responded to another learner's question by asking another question to give a hint to the solution rather than giving away the answer.

As shown in both studies, the way how an experience or idea was shared could impact the dynamic of the ongoing conversations as well as the social relationships among learners. These findings, although not based on MOOCs, highlight the importance of investigating the comments discursively within discussion threads as well as examining the role language plays in socio-constructive processes.

\subsection{A corpus linguistic approach to MOOC discussions}

To harness both the big data available from MOOC online discussions and the rich language data to explore discourse practices employed by learners, Chapter 6 
introduces a mixed methodology, corpus linguistics, to MOOC research. This is also an attempt to promote linguistic perspectives and methodology in the field of education where textual data are investigated. This mixed methodology provides quantitative evidence without reducing the textual data into codes, unlike the content analysis used in previous MOOC research.

A corpus linguistic approach consists of a set of established procedures and methods, including keywords analysis, concordancing, and collocation analysis (to be introduced in the following subsections), that can be used in combination to investigate language use and patterns in large bodies of textual data (McEnery \& Hardie, 2012). All these methods are based on the assumption that with a corpus of a suitable size, recurring (and rare but important) language patterns can be identified and analysed to reveal language usage, discourse practices and language users' construal of the social world and their interactions.

\subsection{Keyword analysis}

Keywords refer to words used statistically significantly more often in the corpus when compared to another corpus, thus suggesting the "aboutness" and "styles" of the corpus under investigation (Baker, 2004). A word is considered a keyword when the $p$-value for the log-likelihood ratio test is $p$-value $<.000000000001$ when comparing to another corpus (Flowerdew, 2008). The keywords found can then be subjected to more in-depth discourse analysis to understand how the keywords are used in discourse practices. In short, keyword analysis is a corpus-driven, or data-driven approach that starts from quantitative analysis, then moves onto qualitative analysis for interpretation.

\subsubsection{Concordancing}

Concordance lines show the word of interest in their co-text, i.e., a span of characters or words, in a vertical format, as shown in Figure 6.1 which is a display from corpus tool Antconc (Anthony, 2017). The usage and senses of the word of interest across the corpus could thus be analysed qualitatively (Sinclair, 2003). It can be considered as the main method for qualitative analysis in corpus linguistics (McEnery \& Hardie, 2012). The concordance lines facilitate the observation of recurrent language patterns around the keyword or word of interest. It is based on the assumption that the meaning or social function of a word is contributed by the other words regularly co-occurring with it.

\subsubsection{Collocation analysis}

Similar to concordancing, collocation analysis is used to examine recurrent language patterns. Collocates refer to words co-occurring often with the word of interest or keyword, typically within a five-word window preceding or following the word. An effect size measure, mutual information $3\left(\mathrm{MI}^{3}\right)$ is used to indicate how much the observed co-occurrence frequency of the two words exceed expected frequency (McEnery \& Hardie, 2012). 


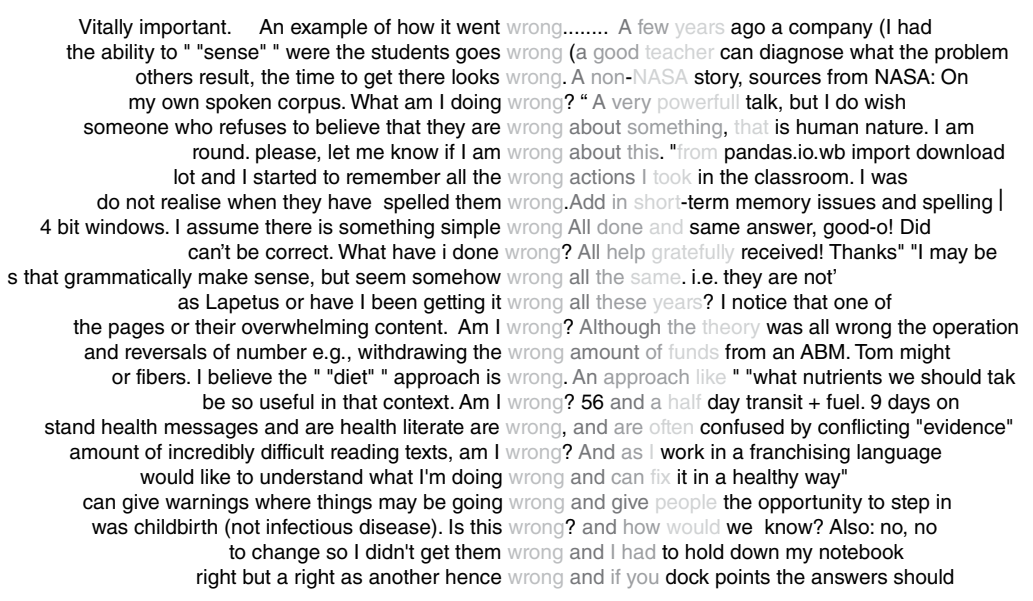

Figure 6.I Concordance lines of wrong in my corpus.

These three procedures reveal repeated patterns of language usage in the corpus, thus facilitating the observation of discourse practices that are common in the language community. Both concordance reading and collocates can be used to further investigate how a keyword is used in a corpus and realises discourse practices.

\subsubsection{Quantitative and qualitative analysis in corpus linguistics}

A corpus analysis typically involves both quantitative analysis and qualitative analysis (Biber, Johansson, Leech, Conrad, \& Finegan, 1999; McEnery \& Hardie, 2012). Quantitative analysis is conducted on the frequency data, i.e., the number of occurrences of words or linguistic patterns in the corpus, typically achieved by keyword analysis, frequency count, and collocation analysis. The qualitative analysis is conducted on the co-text or context where a word occurs in the corpus, typically achieved by concordancing (McEnery \& Hardie, 2012). Both analyses are usually conducted in synergy to examine the form and function of language use (Biber et al., 1999). Forms, that is words, or collocates, are the basis of quantitative analysis, whereas function is examined by the qualitative analysis. Usually, some kind of discourse analysis is conducted for the qualitative analysis alongside concordancing in corpus analysis (Baker, 2004).

\subsection{Previous corpus analysis on MOOCs}

A brief corpus analysis was conducted on a MOOC "How to read your boss" by a corpus linguist (Collins, 2019). Collins employed keyword analysis, concordancing and collocation analysis to investigate learners' use of a technical term taught in the 
MOOC, face, in their comments to explore evidence of their learning. In his corpus, face was found a keyword that was used significantly more often when compared with British National Corpus of written English (BNC, Leech, Rayson, \& Wilson, 2001). However, it was used mainly when learners responded to the discussion prompt in the course materials, "Is 'personal face' or 'social identity face' more appropriate for your workplace?”. This was evidenced by a collocate of face, social identity, which also appeared in the discussion prompt. Collins (2019) found that this technical term was seldom used in other contexts, suggesting that learners might not have acquired the concept of the term to generalise it to other contexts. Nonetheless, Collins' concordancing of the keyword face showed that learners might engage in the socio-constructive process of learning in MOOC discussions. For example, learners explicitly invited others "Would somebody explain the difference between Personal Face and Social Face?" (p. 142) or expressed their uncertainty "I don't feel I fully understand the difference between personal and social face" (p. 142). However, he did not further explore this aspect of learners' discourse.

Collins (2019) also investigated keywords in posts and replies to explore interactivity in the discussions, by comparing each type of comments to BNC. Keywords found in the posts included identity, boss, personal, I, am whereas keywords found in the replies included hi, I agree, you, I, am. However, he did not explore discourse practices realised by these keywords. That is, he stopped at the quantitative analysis of keyword analysis. Collins (2019) himself suggested more in-depth discourse analysis was needed to understand learners' conversations in MOOC discussions.

Although Collins'study focused only on one concept taught in the MOOC, he successfully showed that, besides the often-used coding and counting paradigm, a corpus linguistic approach could reveal textual evidence of users' learning and interactions in MOOCs. He showed that educators could use the corpus methods to examine learners' learning in the MOOCs they teach. He also showed a preliminary finding that discourse in posts and replies were different, although how learners employed the discourse to engage in conversations remained unexplored.

\subsection{Present study: a large-scale corpus analysis of MOOC discussions}

Building on Collins' study (2019), I conducted a large-scale corpus analysis of MOOC discussions in my PhD to explore discourse practices that facilitate or hinder socio-constructive processes of learning. My corpus consisted of 11-million-word learners' contributions (202,787 comments) in 12 FutureLearn MOOCs. For information about FutureLearn, the compilation of the corpus and ethical considerations of analysing learners' comments, readers are referred to my $\mathrm{PhD}$ thesis (Chua, 2020).

In my $\mathrm{PhD}$, I asked the question of how learners initiate and engage with each other in MOOC discussions. To answer this question, I conducted two keyword analyses: (1) comparing posts that receive replies, i.e., initiating posts that initiate a conversation, to those that do not, i.e., independent posts which are not part of a conversation; (2) comparing replies to these two types of posts. The first keyword 
analysis aimed to reveal discourse practices that are more likely to initiate a conversation, while the second keyword analysis to reveal how learners respond and engage with others. The corpus analysis thus provided insights to the beginning and sustaining of the socio-constructive process among learners.

The analysis found 69 keywords of initiating posts (initiating keywords), 77 keywords of independent posts (independent keywords) and 57 keywords of replies (reply keywords). I then conducted concordancing and collocation analysis of each type of keywords to examine the discourse practices realised by these keywords. It is not possible to elaborate and present statistics for every single keyword in Chapter 6 , so in the subsequent sections, only selected findings are summarized, with keywords italicised.

\subsection{Findings}

\subsection{Discourse practices in initiating posts}

Different discourse practices were employed in initiating posts and independent posts. Firstly, compared to independent posts, learners tended to use more modals (might, would, could) and hedges (perhaps, seems, sort of) to soften their claim (e.g., This could perhaps mean that British fiction, in comparison with American fiction, uses more dialogue?) in initiating posts. This softening was also expressed by indicating their uncertainty (I wonder, I am wondering), not knowing (I don't know), possible mistake (I might be wrong, am I missing something?) or if-conditionals. This softening or qualification of one's claim ensured that their posts did not come off as bare assertions or authoritative that did not allow alternative voices (Littleton \& Whitelock, 2005; Martin \& White, 2005). Rather, these initiating posts framed in tentativeness created room for others to pitch in, thereby increasing the chance of receiving replies and beginning a socio-constructive process with others.

Secondly, in the initiating posts, although learners did not know who was going to reply them, they established a dialogue with potential conversational partners with anybody and anyone (e.g., does anybody have a good suggestion; Anyone heard of Hildegard von Bingen's contributions to plantlore?). This framing indicated their invitation to any learners in the MOOC to join their conversations. Besides, these two initiating keywords were also used to seek shared experience or problems (e.g., Anybody else not counting calories?; Anyone ever had HAD to use the old fashioned earth toilet). This framing suggests that learners co-constructed their experience in the discussions. Additionally, learners addressed other users with anyone and anybody, instead of addressing only facilitators, suggesting that learners were aware of the socio-constructive learning function of MOOCs, i.e., learning via conversation with each other, instead of an educator-centred transmission model (Sharples \& Ferguson, 2019).

Thirdly, meta-language, that is language used to explicitly refer to learning or discussion (article, question, example) were also used more frequently in initiating posts. Using these words in their posts to highlight what they referred to (e.g., Question: If climate change is; That was quite hard for me to comprehend the 
article; A fine example can be found) provided a concrete common ground for others to reply to.

In short, discourse practices that indicated tentativeness addressed potential conversation partners, referred explicitly to a common ground seemed to increase the chance of receiving replies and initiating a conversation. The discourse practices facilitated socio-constructive learning by welcoming alternative voices or shared experiences pitched by others, and explicitly referring to issues to be discussed.

\subsubsection{Discourse practices in independent posts}

Learners used fewer initiating keywords and the discourse practices explained above in the independent posts. This might explain why independent posts did not receive replies. In contrast to addressing other learners, in independent posts, learners engaged in self-references (I, my, our) and expressed appreciation (e.g., Excellent range of resources, thanks!). Instead of stating their uncertainty, learners tended to express their learning goals (e.g., I'm really looking forward to learn) or outcomes (e.g., I enjoyed this course and definitely learned a lot). These expressions of selfreferences, appreciation and learning goals and outcomes could be prompted by the learning activities or content at the start (e.g., Describe your interest in ... and ... tell us what you hope to get from this course) and at the end of each MOOC (e.g., What have you found to be good, useful or interesting during this course?). Since learners were responding to the prompts, the posts might not be written to engage with others. Learners' own reflections with the learning activities and content also played an important role in learning (Ferguson \& Sharples, 2014).

Learners also voiced their opinions in independent posts, as evidenced by the independent keywords think and agree (e.g., I think we should be open to the possibility; I agree ... so it enables...). However, nobody joined the conversations to exchange opinions, so the socio-constructive process of engaging with each other did not happen. There were times that learners merely expressed their agreement without further elaboration. Although these agreements indicated their presence in the discussions and created a positive environment, the lack of additional substance in their independent posts might explain why nobody replied to them.

More importantly, most of the independent posts with phrases I think and I agree seemed to be in response to learning activities with prompts "Do you think" and "Do you agree". The framing of the prompts might have primed learners to selfreference and respond to the questions on the page, thus very few learners responded to each other to co-construct their ideas. Admittedly, it is fairly common that internet users respond to content on the page more often than engaging with each other (Herring, 2013). Therefore, the occurrence of independent posts in the discussion was not solely due to the framing of the learning activities.

In short, the discourse practices in the independent posts were mainly appreciation of the MOOC, reflection of learning journey, or voicing of opinions, all of which seemed to be addressed towards the prompts of the learning activities. This might explain why these posts did not receive any reply since these discourse practices did not create room for others to pitch in. 


\subsubsection{Discourse practices in replies}

$91 \%$ of the initiating posts received between one and four replies, suggesting that most conversations among learners in the discussions were relatively short-lived, and might not be conducive for socio-constructive processes. Most replies were expressions of agreement (yes, agree, agreed, true, right, exactly, absolutely, totally, indeed) and expression of appreciation (thanks, thank). The expression of agreement, especially in short replies, might not generate a conversation. However, it was a way for learners to indicate their engagement with the posts, as shown in the short thread below. The expression of agreement could be considered a socio-constructive process of shared experienced.

INITIATING POST: It's interesting that the issues Dyslexic students may extend into aural aspects of language..... I like the idea of focusing on receptive subskills..... I think we often make the mistake of focusing on product over process in learning, and it seems to me that for Dyslexic students, a focus on process is absolutely essential.

REPLY I: Yes - I'm guilty of this.

REPLY 2: I would strongly agree with that!

Although the reply keyword agree and agreed were mainly used for expressing agreement, the concordance reading of agree revealed that users employed the phrase agree to disagree/differ in replies, especially in long discussion threads. The phrase was used to end their discussions when they could not reach agreement after voicing their disagreement. In these conversations, although they did not manage to co-construct a final verdict, they were at least exposed to different views, suggesting socio-constructive learning.

Another discourse practice found in replies was indication of tentativeness, similar to the discourse practices in initiating posts. However, it was realised with hedges maybe and probably, which are used more often in oral language, suggesting the dialogic nature of replies (Biber et al., 1999). The function of these two hedges in a socio-constructive process is best illustrated in one discussion where a few learners employed these two hedges to provide advices to a learner who posted about difficulties in providing their stepchildren a healthy diet. Two of the replies were shown here. The numbering of the replies indicated its order within the discussion thread.

REPLY 3: ..... The idea of a family meal in your case sounds pretty hellish but, maybe, there are other things going on in their minds and it is not just food?......

REPLY 9: It must be soul-destroying for you, but you are probably wise not to let meals become more of a battleground......

In these two replies, the hedges made the advice-giving less directive and authoritative. This was evidenced by other replies by learners contributing these 
two replies, "Hope that doesn't sound awfully patronising!" "sorry if it sounds simplistic". The learner who asked for advice also took on the advice by saying "Thank you everybody for your comments, I am agreeing and.....". The hedges might have created room for the learner to respond to the advice and explain their situations more. The advice-giving and learner's further explanation in response to the advice suggested that learners engaged in a socio-constructive process.

Another discourse practice found in the replies was meta-language referring to each other's comments (reply, posting, comment, post, point, said, say, you, your), suggesting that learners engaged with others' comments. The meta-language could be a double-edged sword. On one hand, it was used to clarify each other's comments, and facilitate resolution of misunderstanding, as shown in the following exchange between two learners.

REPLY 4: I did not say it is a waste but it seems to be a waste if you dispose of it without taking any benefits from it.....

REPLY 5: sorry, I thought you said supplements with added protein are clearly a money making scheme. It does make you think though, which is the point of the course.....

On the other hand, using meta-language to question others' comments without acknowledging their clarification could lead to stalemate in a discussion, hindering the socio-constructive process. The exchange below illustrates this situation, which came from a discussion thread where these two learners repeatedly criticized each other's comments.

REPLY 4: ..... In another post, about apple cider vinegar, you specifically say 'Two words - Take It.' In this post you tell us 'trust me, it works'. That sounds to me as if you are recommending it to anyone who reads that comment......

REPLY 5: ......It seems as though you consider my phrasing to have been flippant but you don't have to post long, in-depth comments on everything......

In short, learners' discourse in replies indicated their engagement with others' comments, although most discussions were short-lived. Expressions of agreement and appreciations created a positive space in the discussions, while framing responses with tentativeness facilitated co-constructions of solutions. Meta-language seemed to be useful to clarify misunderstanding for socio-constructive learning, but overusing it could lead to stalemate.

It is worth noting that a keyword analysis comparing replies in long conversations (more than five replies) versus short conversations (fewer than five replies) found no keywords in long conversations, suggesting either that there might not be any word or expression that could increase the chance of sustaining a thread, or that discourse practices sustaining a thread were not realized by particular keywords or expressions. Therefore, an in-depth discourse analysis was conducted to further examine long threads in my $\mathrm{PhD}$, which will be presented in future publications. 


\subsubsection{Unexpected reply keyword: link}

As mentioned earlier, keyword analysis is a data-driven approach that could unravel unexpected observations in the data. One such observation was the reply keyword, link, which was used by learners to refer to URLs. Based on concordance reading and collocation analysis, learners typically appreciated others posting link(s) in the discussions (see Figure 6.2). However, very seldom did the URLs posted generate a discussion, and learners sometimes did not write much about the URLs posted, as shown below.

Eat it. Much better for you than seed oils and polyunsaturates. https://www. ncbi.nlm.nih.gov/pubmed/24723079

There were a few rare cases where learners discussed extensively about URLs posted, suggesting a socio-constructive process. This happened when the learners held on opposing views and each posted URLs to support their own views. Although it is encouraging that learners critiqued each other's posted URLs, they seldom discussed the content linked to the URLs but the credentials of the authors. Most of the time, they remained unconvinced by each other's posted URLs and arguments. Learners may need to be prompted to move beyond the URL itself but to discuss the content linked to the URL to facilitate the socioconstructive process.

\subsection{Discussion and moving forward}

MOOC discussion is a space where learners engage with each other to exchange information and ideas. Commenting in the online discussions differ from oral or written language, such that learners need to be equipped with language skills suitable for communicating and learning in this new medium (Herring, 2013; Littleton \& Whitelock, 2005). However, previous MOOC research has not yet

\footnotetext{
only managed to find her interview in Guardian. Thanks Michele, for the link to exercises on concordances. nts and research funds. Very interesting Julian, thanks for that link @Carole Pope. Hi Carole, I the link. Thanks for the link! Very helpful! "Thanks for the link! When I live on Mars aters in the maria adn craters within craters. " Thanks for the stellarium link:) "Do you have a eiYzRfd2taTFplQ0U/BE06_AntConc_compat.txt" Thanks for he link Simon. The by-products of that comes up Three days behind ya, Andy! Thanks for this link. Are these telescopes in orbit $y+23 \% 2 C+2008$ very useful link Thanks for the link Phil, very interesting. Many thanks for the link which confirm that the view noted in the link has been superceded. "Many thanks David for your I think that they will be to you." Thanks for the MMM link, Carol. I'm already

to funding the wars etc that Mike mentions." Thanks Mark, great link shows just how bad "common have a look at your account of spelling: thanks for sharing the link. "Thank you for the 't work Jonathan, that is such a useful link! Thank you - Thanks for your comments and the soil horizon photo with helpful measurements. Thanks for the link to Soil Science page. (I'
}

Figure 6.2 Concordance lines of link in my corpus. 
paid attention to the language use in the discussion. By conducting a corpus analysis of 12 MOOC Futurelearn courses, Chapter 6 successfully unveiled useful discourse practices that learners can employ to initiate and engage in conversations with others in MOOC discussions. The analysis showed that there were indeed differences between initiating posts that receive replies, independent posts that do not receive replies, and replies.

Chapter 6 illustrated that a corpus linguistic approach is useful for examining big language data available from MOOC discussions while enabling discourse analysis of actual language usage at the same time. This mixed methodology revealed both the general patterns and specific discourse practices in the discussion. The quantitative component of keyword analysis or collocation analysis pointed to a specific keyword or collocate which discourse functions were examined qualitatively by concordancing.

More importantly, this integration of quantitative and qualitative analysis can guard against the possible presumption of the researchers regarding the discourse functions of certain words. For example, the keyword wrong did not necessarily carry a negative meaning but was used typically by learners to express their uncertainty, whereas the keyword link was not used to establish logical reasoning, but to refer to a URL posted. Both keywords wrong and link might be coded otherwise in coding and counting paradigm in other MOOC research, which might prevent us from understanding learners' actual discourse. Furthermore, current machine-learning techniques used in MOOC research (e.g., Wise et al., 2016) and discussed in Chapter 13 (Hillaire, Rienties, Fenton-O'Creevy, Zdrahal, \& Tempelaar, 2022) typically discard function words, such as modals, grammatical words, and pronouns which have been well-established as linguistic resources for social relationships (Biber et al., 1999). As shown in Chapter 6, some modals were used to initiate conversions with others. This shows that a corpus linguistic approach may have much to offer for exploration of discourse practices for socio-constructive processes.

\subsection{Implications for practice}

Based on the findings in Chapter 6, several writing tips for online discussions can be provided for learners and facilitators:

1 Do not make sweeping generalizations and bare assertions. Rather, use modals, hedges, if-conditionals to soften or qualify your claims, such that others' alternative views are not rejected.

2 Express uncertainty and tentativeness in your claims, such that others will be more willing to fill in the gap.

3 Be explicit in referring to the issue or topic you are writing about, such that a common ground can be established.

4 Use oral language to address potential audience, and seek others who share similar experiences or problems.

5 Recognize others' viewpoints and acknowledge what others have written. 
6 You can agree to disagree, rather than having a "winner" in a debate.

7 It is ok to ask for clarification from others regarding their comments, but do not repeatedly criticize their ways of posting.

8 Write about the relevance of the URLs to the current discussions.

The findings in Chapter 6 could also inform design of the discussion prompts. Although the prompts "Do you think" and "Do you agree" typically introduce a question that requires learners to voice their opinions, this framing inevitably prompt learners to post rather than replying to others. Perhaps additional prompts such as "How do you find others' view in relation to yours?" can be added. At the same time, the number of questions in the prompts can be reduced, such that learners have a focused common ground to engage with each other. Nonetheless, the effectiveness of this suggestion awaits to be examined. It is also worth reiterating that online users tend to post in response to content on the page than respond to others. Therefore, it is unavoidable learners do not necessarily reply to others but the prompts.

\section{References}

Almatrafi, O., \& Johri, A. (2019). Systematic review of discussion forums in Massive Open Online Courses (MOOCs). IEEE Transactions on Learning Technologies, 12(3), 413-428. doi:10.1109/TLT.2018.2859304

Anthony, L. (2017). AntConc. Tokyo, Japan:Waseda University. Retrieved from http://www. laurenceanthony.net/software/antconc/

Baker, P. (2004). Querying keywords: questions of difference, frequency, and sense in keywords analysis. Journal of English Linguistics, 32(4), 346-359. doi:10.1177/ 0075424204269894

Biber, D., Johansson, S., Leech, G., Conrad, S., \& Finegan, E. (1999). The Longman grammar of spoken and written English. London: Longman.

Chua, S. M. (2020). The dialogic nature of online discourse: a corpus analysis of online discussions. Milton Keynes: The Open University.

Collins, L. (2019). Corpus linguistics for online communication: a guide for research. New York: Routledge.

Conde Gafaro, B. (2022). First steps towards self-regulated learning: setting goals in MOOCs. In B. Rienties, R. Hampel, E. Scanlon, \& D. Whitelock (Eds.), Open world learning: research, innovation and the challenges of high-quality education (pp. 63-75). London: Routledge.

Ferguson, R., \& Sharples, M. (2014). Innovative pedagogy at massive scale: teaching and learning in MOOCs. In C. Rensing, S. de Freitas, T. Ley, \& P. J. M. Merino (Eds.), Open learning and teaching in educational communities, proceedings of 9th European conference on technology enhanced learning (EC-TEL 2014), Graz, Austria, September 16-19 (pp. 98-111). Heidelberg: Springer.

Flowerdew, L. (2008). Corpus-based analyses of the problem-solution pattern. Amsterdam / Philadelphia: John Benjamins Publishing Company.

Herring, S. (2004). Computer-mediated discourse analysis: an approach to researching online communities. Designing for Virtual Communities in the Service of Learning, 338-376. doi:10.1017/CBO9780511805080.016

Herring, S. (2013). Discourse in Web2.0: familiar, reconfigured and emergent. In D. Tannen \& A. M. Tester (Eds.), Discourse 2.0: language and new media (pp. 1-29). Washington, DC: Georgetown University Press. Retrieved from http://info.ils.indiana.edu/ herring/ GURT.2011.prepub.pdf 
Hillaire, G., Rienties, B., Fenton-O'Creevy, M., Zdrahal, Z., \& Tempelaar, D. (2022). Incorporating student opinion into opinion mining: a student sourced sentiment analysis classifier. In B Rienties, R. Hampel, E. Scanlon, \& D. Whitelock (Eds.), Open world learning: research, innovation and the challenges of high-quality education (pp.171-186). London: Routledge.

Iniesto, F., McAndrew, P., Minocha, S., \& Coughlan, T. (2022). Accessibility in MOOCs: the stakeholders' perspectives. In Bart Rienties, R. Hampel, E. Scanlon, \& D. Whitelock (Eds.), Open world learning: research, innovation and the challenges of high-quality education (pp. 119-130). London: Routledge.

Kääntä, L., \& Lehtinen, E. (2016). Patterns of experience talk and argumentation in digital peer learning discussions.Language@Internet, 13,1-15.

Kellogg, S. B., Booth, S., \& Oliver, K. M. (2014). A social network perspective on peer support learning in MOOCs for educators. International Review of Research in Open and Distance Learning, 15(5), 263-289. https://doi.org/10.19173/irrodl.v15i5.1852

Leech, G., Rayson, P., \& Wilson, A. (2001). Word frequencies in written and spoken English: based on the British National Corpus. London: Longman.

Littleton, K., \& Whitelock, D. (2005). The negotiation and co-construction of meaning and understanding within a postgraduate online learning community. Learning, Media and Technology, 30(2), 147-164. doi:10.1080/17439880500093612

Martin, J. R., \& White, P. R. R. (2005). The language of evaluation: appraisal in English. UK: Palgrave Macmillan.

McEnery, T., \& Hardie, A. (2012). Corpus linguistics: method, theory and practice, 312. doi:10.1017/CBO9781107415324.004

Poquet, O., Dowell, N., Brooks, C., \& Dawson, S. (2018). Are MOOC forums changing? In Proceedings of the 8th international conference on learning analytics and knowledge (LAK'18) (pp. 340-349). New York: ACM. https://doi.org/doi:10.1145/3170358.3170416

Rizvi, S., Rienties, B., Kizilcec, R., \& Rogaten, J. (2022). Culturally adaptive learning design: a mixed-method study of cross-cultural learning design preferences in MOOCs. In Bart Rienties, R. Hampel, E. Scanlon, \& D. Whitelock (Eds.), Open world learning: research, innovation and the challenges of high-quality education (pp. 103-116). London: Routledge.

Sharples, M., \& Ferguson, R. (2019). Pedagogy-informed design of conversational learning at scale. In A. Fessl \& T. Z. Draksler (Eds.), ECTEL practitioner proceedings 2019: 14th European conference on technology enhanced learning (Vol. 2437).

Sinclair, J. (2003). Reading concordances: an introduction. London: Pearson.

Vygotsky, L. (1978). Mind in society. Cambridge, MA: Harvard University Press.

Wang, X., Wen, M., \& Rosé, C. P. (2016). Towards triggering higher-order thinking behaviors in MOOCs. Proceedings of the 6th International Conference on Analytics and Knowledge, (November), 398-407. https://doi.org/http://dx.doi.org/10.1145/2883851.2883964

Wegerif, R., \& Mercer, N. (1997). Using computer-based text analysis to integrate qualitative and quantitative methods in research on collaborative learning. Language and Education, 11(4), 271-286. doi:10.1080/09500789708666733

Wen, M.,Yang, D., \& Rosé, C. P. (2014). Sentiment analysis in MOOC discussion forums: what does it tell us? In Proceedings of the Seventh International Conference on Educational Data Mining (EDM 2014) (pp. 130-137). Massachusetts: International Educational Data Mining Society.

Wise, A. F., Cui, Y., \& Vytasek, J. (2016). Bringing order to chaos in MOOC discussion forums with content-related thread identification. In Proceedings of the Sixth international conference on learning analytics E knowledge - LAK'16 (pp. 188-197). New York:ACM Press. doi:10.1145/2883851.2883916

Wise, A. F., \& Paulus, T. M. (2016). Analyzing learning in online discussions. In C. Haythornthwaite, R. Andrews, J. Fransman, \& E. Meyers (Eds.), The SAGE handbook of e-learning research (2nd ed., pp. 270-290). Sage Publications. 